\title{
Bom crioulo: uma narrativa naturalista silenciada pelos cânones
}

\section{Rondinele Aparecido Ribeiro ${ }^{1}$}

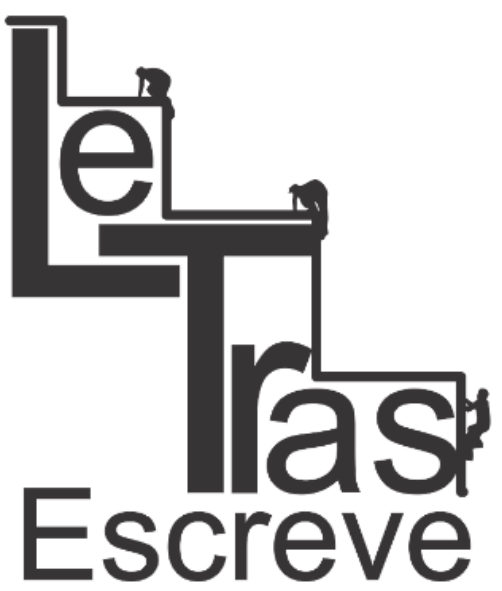

(ISSN 2238-8060)

Resumo: Publicado em 1895, o romance Bom Crioulo causou muita polêmica na sociedade por ser o primeiro romance brasileiro que empregou protagonistas personagens que vivem uma relação homossexual: o negro Amaro e o jovem Aleixo. Mesmo que se enquadre nos ideais estéticos do Realismo-Naturalismo, esse romance foi esquecido pela tradição canônica, tendo sido redescoberto apenas nos anos 1950. Dessa forma, o presente artigo tem como objetivo apontar o motivo de tal silenciamento dessa obra pelo cânone nacional.

Palavras-chave: Realismo. Cânone. Bom Crioulo. Silenciamento.

Abstract: Published in 1895, the novel Good Creole caused much controversy in society by being the first Brazilian novel that employed protagonists characters living a homosexual relationship: Amaro black and the young Alexius. Even that fits the aesthetic ideals of Realism, Naturalism, this novel has been forgotten by the canonical tradition and was rediscovered only in 1950. Thus, this article aims to point out the reason for such silencing of such work by the national canon.

Keywords: Realism . Canon. Good Creole . Muting .

\section{Introdução}

Em meados do século XIX, a Europa experimenta uma forte reação à estética romântica desencadeada pelo progresso definitivo das ciências, a industrialização e o florescimento de novas correntes filosóficas, que foram responsáveis por gerar um ambiente de superação ao sentimentalismo romântico. Nesse período, os escritores acabam voltando sua produção para uma linguagem objetiva capaz de retratar e documentar a realidade. Assim, pode-se dizer que "a arte realista-naturalista correspondeu ao período de consolidação do poder

\footnotetext{
${ }^{1}$ Mestrando em Letras pela UNESP-ASSIS (linha Literatura e Estudos Culturais). Membro do GP Cultura Popular e Tradição Oral: Vertentes. Especialista em Cultura, Literatura Brasileira e Língua Portuguesa. Licenciado em Letras-Literatura pela UENP. Contato: rondinele-ribeiro@bol.com.br
}

https://periodicos.unifap.br/index.php/letras

Macapá, v. 7, n. 4, 2 semestre, 2017 


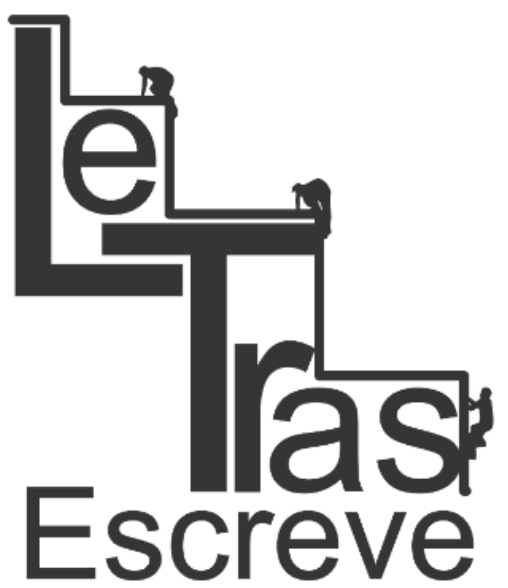

(ISSN 2238-8060) político da burguesia, na segunda metade do século XIX" (ABDALLA; CAMPEDELLI, 2004, p.132).

Percebe-se, a partir das reflexões iniciais, que o século XIX um período bastante sui generis no que se refere ao modo como o homem irá moldar sua percepção diante de um mundo cada vez mais problemático. Tal percepção será atingida, evidentemente, por meio do amplo papel investigativo sobre a realidade e constituição do rearranjo humano. A grande verdade é que definir um conceito de Realismo - Naturalismo não é uma tarefa das mais simples, sobretudo, porque a objetividade pregada pelo movimento não foi uma característica isolada de tal estética. Por esse motivo, Abdalla e Campedelli (2004, p.133) postulam que "o conceito de Realismo-Naturalismo é bastante amplo". Na obra intitulada Tempos da Literatura Brasileira, os estudiosos apontam que ocorreram tendências realistas em muitos períodos literários.

Silvana Oliveira (2008), em sua obra Realismo na Literatura Brasileira, defende a tese de que a literatura da segunda metade do século XIX é marcada pelos preceitos realistas pelo fato de adotar uma nova perspectiva para a abordagem da realidade sem as marcas de subjetividade romântica. Instaurada no país, em 1881 com a publicação do romance $O$ Mulato, de Aluísio Azevedo, a corrente estética denominada de Naturalismo "pode ser compreendida como uma radicalização dos preceitos realistas, principalmente no que tange à concepção determinista do comportamento humano (OLIVEIRA, 2008, p.57).

Oliveira (2008) sustenta ainda que "o conceito de Realismo sempre teve associado à prática literária". Para tanto, a estudiosa explica que a representação da realidade permeia o espaço literário desde as concepções aristotélicas para quem a literatura deve apre-

https://periodicos.unifap.br/index.php/letras

Macapá, v. 7, n. 4, 20 semestre, 2017 


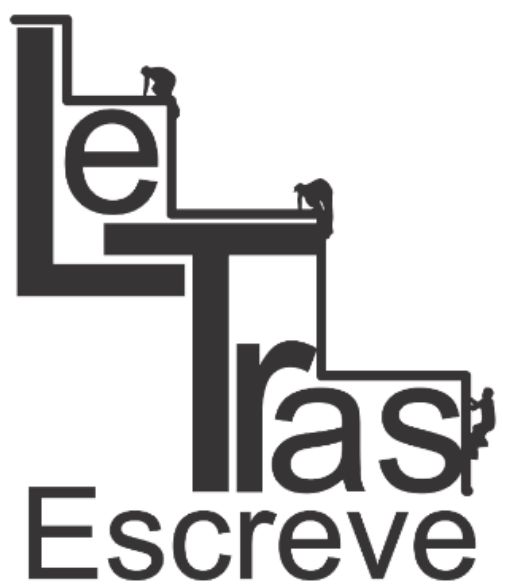

(ISSN 2238-8060)

sentar ou representar a realidade. Dessa forma, a definição para o termo Realismo ganha contornos mais definidos quando se constata que a literatura produzida pelo período acaba voltando sua observação para a realidade enfocando situações cotidianas e representativas. Nas palavras de Campedelli e Barbosa (1999, p.155), “O Realismo é uma arte engajada, que tem como compromisso o momento presente e com a observação objetiva e exata do mundo".

Um dos grandes impulsos para a propagação do movimento Realista-Naturalista foi o surgimento de teorias cientificistas. Dessa forma, Positivismo, Determinismo e Darwinismo foram de grande importância para essa estética, uma vez que tais teorias estavam preocupadas em explicar a condição do homem enquanto um ser social. Assim, os escritores vão recorrer frequentemente a tais teorias para explicar o comportamento dos personagens representativos de seus romances.

Apesar do ponto comum entre as duas estéticas, é possível delinear grandes diferenças entre as duas. Dessa forma, para Campedelli e Barbosa (1999), "o Naturalismo seria um Realismo exacerbado, uma forma mais aprofundada de encarar o homem". Silvana Oliveira (2008, p. 57), também contribui ao definir o Naturalismo como "uma radicalização dos preceitos realistas, principalmente no que tange à concepção determinista do comportamento humano".

Para esclarecer ainda mais sobre as diferenças entre Realismo e Naturalismo, é oportuno recorrer às definições de Abdalla e Campedelli:

O Naturalismo surgiu no Brasil como uma "literatura imoral", em face dos preconceitos provincianos. $\mathrm{Na}$ verdade, sua ação teve caráter reformista: uma adequação do país aos padrões estéticos e ideológicos mecanicistas da Europa industrializada. Ao pre- 
conizar uma arte participante, levou a literatura a contribuir de forma ativa para a renovação da vida brasileira. Temas ou assuntos característicos do $\mathrm{Na}$ turalismo - como o anticlericalismo, o republicanismo, a luta contra o preconceito racial e contra o puritanismo sexual - permitiram novas definições sócio-culturais sobre a identidade do país. (ABDALLA, CAMPEDELLI, 2004, p. 138)

Opera-se uma diferença fundamental entre Realismo e Naturalismo. Para o escritor realista, interessa enfocar a realidade de maneira objetiva, valendo-se do romance documental. Já para o escritor naturalista, o interesse é movido pelo caráter experimental de submeter o comportamento humano. Opera-se com o consenso de que o naturalismo é responsável pela deformação da identidade pelo fato

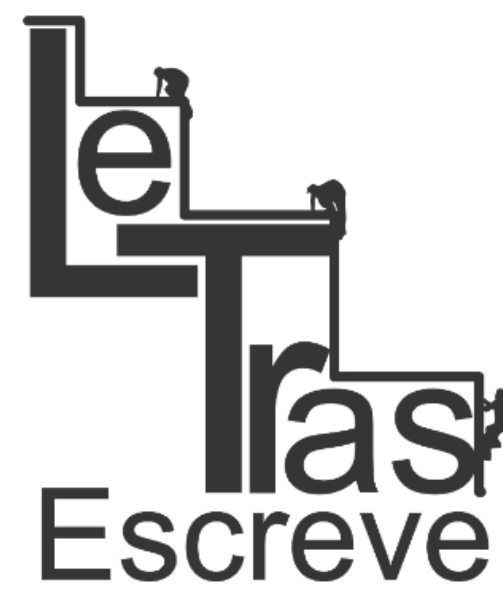

(ISSN 2238-8060) de recorrer ao traço determinista na caracterização das personagens. A partir da exposição feita pelos estudiosos em questão, pode-se pontualmente asseverar que a literatura desse período irá recorrer ao cientificismo bem como ao grotesco para compor um verdadeiro painel da sociedade, comprovando que as ações humanas são na verdade explicadas por meio de aspectos biológicos, fisiológicos, científicos.

O escritor Adolfo Caminha integra o rol de rejeitados pelos cânone literário. Sua obra Bom Crioulo, publicada em 1895, tematiza uma questão considerada extremamente avançada para a época em que foi produzida: o relacionamento homossexual entre militares. Ao dimensionar essa temática e situá-la no universo experimental, o escritor escancara um tema considerado tabu e o aloca numa instituição considerada sagrada. Por esse motivo, o romance enquadra-se no perfil de obra que ganhou o status de romance maldito devido ao julgamento negativo feito pela crítica da época.

Tendo como enredo a tragicidade determinista marcada por

https://periodicos.unifap.br/index.php/letras

Macapá, v. 7, n. 4, 20 semestre, 2017 


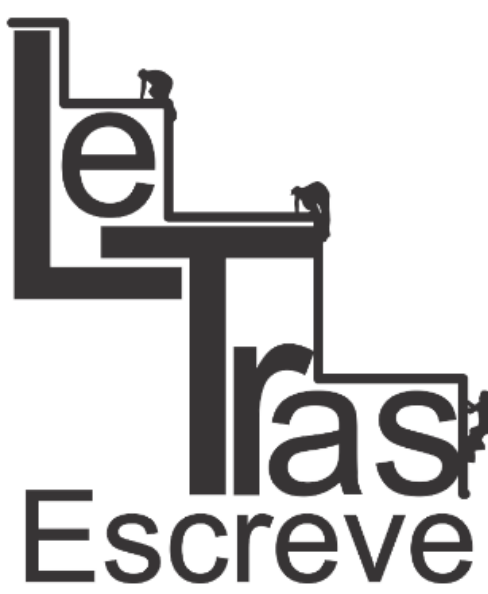

(ISSN 2238-8060) uma relação homossexual e um triângulo amoroso, o romance enfoca as ações entre Amaro e Aleixo, ambos marinheiros. Os dois vivem um relacionamento sexual apresentado na obra pela linguagem extremamente experimental. Os dois alugam um quarto para manterem tal relacionamento, mas Aleixo tem uma mudança de comportamento e passa a ser amante de Carolina, a portuguesa dona de uma pensão. Amaro, descobre a traição e assassina o companheiro no meio da rua, ou seja, tudo ocorre no universo naturalista de recorrer ao emprego do patológico e do experimentalismo para explicar as ações humanas. A partir de tais considerações, o presente artigo volta-se para a análise de uma obra Naturalista silenciada pelos cânones e que foi redescoberta apenas a partir dos anos 1950.

\section{Sobre autor e obra}

Adolfo Caminha nasceu no dia 29 de maio de 1867 e morreu no Rio de Janeiro no dia 1 de janeiro de 1897 . Foi um dos principais autores do Naturalismo no Brasil. Era filho de Raymundo Ferreira dos Santos e Maria Firmina Caminha. Mudou-se para o Rio de Janeiro, ainda na infância. Em 1883, Adolfo entra para a Marinha de Guerra, chegando ao posto de segundo-tenente. Cinco anos mais tarde, transfere-se para Fortaleza (1888). Apaixona-se por Isabel de Paula Barros, a esposa de um alferes, que abandona o marido para viver com Caminha. O casal teve duas filhas: Belkiss e Aglaís. Na sequência do escândalo, vê-se obrigado a deixar a Marinha e passa a trabalhar como funcionário público, na cidade do Rio de Janeiro.

A sua primeira obra publicada foi Voos Incertos (1886), um livro de poesia. Em 1893, Adolfo publica A Normalista, romance em que traça um quadro pessimista da vida urbana. Usa as suas experi-

https://periodicos.unifap.br/index.php/letras

Macapá, v. 7, n. 4, 2ㅇ semestre, 2017 
ências e observações de uma viagem que havia feito aos Estados Unidos em 1886, para escrever No País dos lanques (1894). No ano seguinte, provoca escândalo, mas firma sua reputação literária ao escrever Bom Crioulo, abordando a questão da homossexualidade. Fundou a "Revista Moderna" em 1891 e, em 1892, a "Padaria Espiritual”, movimento que acreditava na educação do povo para mudar o país, e publicava o jornal "O Pão". O escritor colaborou também com a imprensa carioca, em jornais como Gazeta de Notícias e Jornal do Commercio, e fundou o semanário Nova Revista. Seu último romance foi Tentação, datado de 1896. Caminha faleceu em 1897, aos 30 anos.

Apesar de Bom Crioulo não ser a primeira experiência na litera-

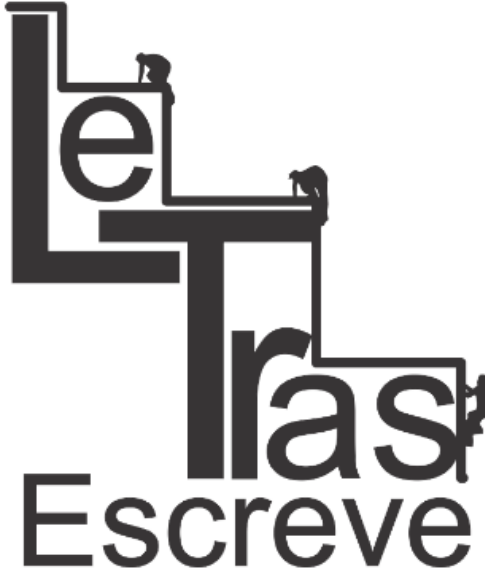

(ISSN 2238-8060) tura brasileira a enfocar a temática homossexual, é a que obteve a maior polêmica quanto à recepção do público e da crítica especializada. Sobre o emprego da temática homoerótica, a obra $O$ barão de Lavos, datada de 1891, do escritor português Abel Botelho, é considerada um marco. Do mesmo modo, pode ser citada ainda a obra Um homem gasto, datada de 1885, do escritor Ferreira Leal, praticamente desconhecido do público e, até mesmo, da crítica. Também pode ser citada a obra O Ateneu, e Raul Pompeia

Como já afirmado, a obra de Caminha ficou esquecida dos cânones literários durante um bom tempo. Apenas no século XX a obra passou a ser objeto de estudos na esfera literária. A obra de Caminha foi recebida como imoral supostamente por tratar de um tema abjeto. "O tema já de si abjeto, é tratado de modo que o torna extremamente chocante, com pormenores de todo em todo desnecessários, por vezes com um mau gosto declamatório espantoso num escritor da categoria de Adolfo Caminha" (MIGUEL-PEREIRA, 1960, p. 9). Para a estudiosa em questão, o romance tem status de ousado na concepção, na execução e ao lado de $O$ Cortiço é o ponto alto do Naturalis- 
mo.

A partir da breve apresentação acerca do enredo da obra cotejada, percebe-se o quão vasta é seu estudo investigativo no sentido de estudar a representação experimental a que os personagens são submetidos. Assim, percebe-se que o personagem Amaro tem seu comportamento alterado no decorrer da narrativa e o leva a traços passionais, já que assassina seu antigo amor, o marinheiro Aleixo. Amaro é o primeiro protagonista homossexual negro da Literatura Brasileira, portanto sendo retratado por um romance naturalista, é de esperar os grandes traços deterministas típicos da estética em questão. A complexidade desse personagem é ainda maior quanto ao critério do tipo social. Amaro é um militar, sendo homossexual, era de se esperar que a obra não tivesse uma recepção amistosa na época da publicação.

Não faltaram adjetivos para qualificar a obra como "obscena", "imoral", "romance-vômito", "escabrosa", "imunda". Em se tratando do herói problemático, Amaro, em sua primeira descrição, é caracterizado como "figura exótica de um marinheiro negro, de olhos muito brancos, lábios enormemente grossos, abrindo-se num vago sorriso (ISSN 2238-8060) idiota, em cuja fisionomia acentuavam-se linhas características de estupidez e subserviência" (CAMINHA, 2009, p.27).

Estruturada em 12 capítulos, o romance inicia focalizando a tripulação em alto-mar submetida a uma luz intensa e a um forte calor asfixiante. Três marinheiros são castigados recebendo chibatadas, fato que interrompe a calmaria no navio: o adolescente Herculano (flagrado masturbando-se), Sant'Ana (quem flagrou Herculano e o agrediu) e Amaro (por ter agredido um colega que importunara o jovem Aleixo, marinheiro jovem de olhos azuis por quem Amaro mantinha um carinho especial).

https://periodicos.unifap.br/index.php/letras

Macapá, v. 7, n. 4, 20 semestre, 2017 
Percebe-se na obra um tom forte de denúncia acerca da aplicação do castigo corporal a que os marinheiros eram submetidos. Vale lembrar que as chibatadas eram um costume antigo da marinha, constituindo-se no motivo maior para o levante ocorrido durante o governo de Hermes da Fonseca, em 1910. Sendo um levante de cunho social, realizado em subdivisões da Marinha, sediadas no Rio de Janeiro.

A personagem protagonista da obra é o marinheiro Amaro, tratado por Bom Crioulo. Sua origem vem apresentada no segundo capítulo do romance. Trata-se de um escravo fugitivo de uma fazenda de café, cansado da vida que levava, em busca de condições melhores que, até certo ponto, foram encontradas na marinha onde aprendeu

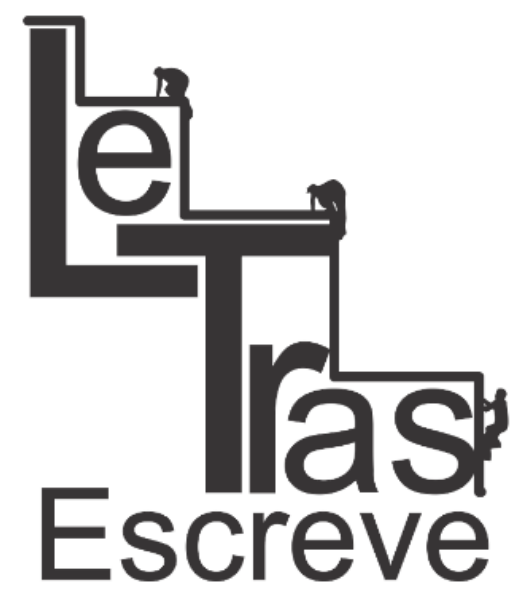

(ISSN 2238-8060) o ofício:

A disciplina militar, com todos os seus excessos, não se comparava ao penoso trabalho na fazenda, ao regime do terrível tronco e do chicote. Havia muita diferença... ali ao menos, na fortaleza, ele tinha sua maca, seu travesseiro, sua roupa limpa e comia bem, a fartar, como qualquer pessoa[...] Para que melhor? (CAMINHA, 2009, p.22)

Na sequência, tem-se descrição de Amaro:

[...] um latagão de negro, muito alto e corpulento, figura colossal de cafre, desafiando, com um formidável sistema de músculos, a morbidez patológica de toda uma geração cadente e enervada, e cuja presença ali naquela ocasião, despertava grande interesse e viva curiosidade: era o Amaro, gajeiro da proa - o Bom Crioulo na gíria de bordo. (CAMINHA, 2009, p. 35)

Já na embarcação, Amaro conquista a admiração de todos. Deve-se destacar que a personagem é apresentado inicialmente como 
bastante cordial, calmo, bondoso e prestativo, podendo-se concluir que sua caracterização enseja os traços típicos do herói romântico: “Nunca, durante esse primeiro ano de aprendizagem, merecera a pena de um castigo disciplinar: seu caráter era tão meigo que os próprios oficiais começaram a tratá-lo por Bom-Crioulo" (CAMINHA, 2009, p.26).

Um dado característico na obra e presente em todo romance naturalista é animalização empregada para representar os personagens. Essa técnica, que consiste em rebaixar os seres humanos a animais é recorrentemente empregada como forma de mostrar a degradação comportamental pela qual as personagens passam. Assim, em vários momentos da narrativa, Caminha utiliza-se desse artifício para representar o negro. Para exemplificar, "o negro parecia uma fera desencarcerada" (CAMINHA, 2009, p. 36).

O aspecto comportamental de Amaro é retratado pelo forte viés determinista: "manso quando se achava em estado normal, longe de qualquer influência alcoólica" (CAMINHA, 2009, p. 37). Em outro trecho, tem-se mais exemplos da animalização: "entrou para a marinha rude como um selvagem (...), mas no fim de alguns meses (ISSN 2238-8060) todos eram de parecer que o negro dava para gente (...)" (CAMINHA, 2009, p.41). Para retratar o comportamento de Bom Crioulo, tem-se o seguinte trecho: "Hoje manso como um cordeiro, amanhã tempestuoso como uma fera. Cousas do caráter africano" (CAMINHA, 2009, p.77)

O trecho exemplifica a alteração comportamental experimentada por Amaro. Essa inconstância típica do personagem naturalista é descrita por meio de comparações elaboradas por um forte traço de animalização.

A relação entre os dois amantes também é marcada pela forte

https://periodicos.unifap.br/index.php/letras

Macapá, v. 7, n. 4, 20 semestre, 2017 
descrição animalista:

Uma coisa desgostava o grumete: os caprichos libertinos do outro. Porque Bom-Crioulo não se contentava em possuí-lo a qualquer hora do dia ou da noite, queria muito mais, obrigava-o a excessos, fazia dele um escravo, uma "mulher à-toa" propondo quanta extravagância Ihe vinha à imaginação. Logo na primeira noite exigiu que ele ficasse nu, mas nuzinho em pelo: queria ver o corpo [...]. (CAMINHA, 2009, p.78)

Assim, o relacionamento que se inicia por meio de uma gratidão, ganha contornos extremamente naturalistas, sendo o desejo de Amaro por Aleixo retratado da seguinte forma: "faltavam-lhe os seios

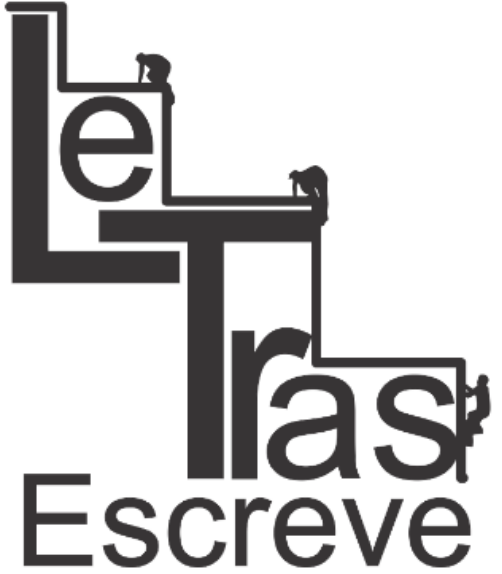

(ISSN 2238-8060) para que Aleixo fosse uma verdadeira mulher (...), dentro do negro rugiam desejos de touro ao pressentir a fêmea..." (CAMINHA, 2009, p.79).

A relação homossexual é tratada com crueza e sem nenhum indício de preconceito pelo escritor naturalista, que vê no vício um objeto de estudo que deve ser esclarecido e compreendido. O desejo sexual do negro é encarado como uma espécie de componente de sua condição enquanto negro.

Nunca se apercebera de semelhante anomalia, nunca em sua vida tivera a lembrança de perscrutar suas tendências em matéria de sexualidade. As mulheres o desarmavam para os combates do amor, é certo, mas também não concebia, por forma alguma, esse comércio grosseiro entre indivíduos do mesmo sexo; entretanto, quem diria! O fato passava-se agora consigo próprio, sem premeditação, inesperadamente. E o mais interessante é que "aquilo" ameaçava ir longe para mal de seus pecados... Não havia jeito senão ter paciência, uma vez que a natureza impunha-lhe esse castigo (CAMINHA, 2009, p.46). 
O homossexualismo, encarado no romance como vício ou perversão, é tratado, portanto, através de um olhar naturalista e, consequentemente, limitado: não há o enfoque mais subjetivo dos sentimentos despertados; não há autonomia do caráter: as personagens estão acorrentadas às leis deterministas (não há drama de consciência ou mesmo drama moral). Assim:

Afinal de contas era homem, tinha suas necessidades, como qualquer outro: fizera muito em conservar-se virgem até os trinta anos, passando vergonhas que ninguém acreditava, sendo muitas vezes obrigado a cometer excessos que os médicos proíbem. De qualquer modo estava justificado perante sua consciência, tanto mais quanto havia exemplos ali mesmo a bordo, para não falar em certo oficial de que se diziam cousas medonhas no tocante à vida particular. Se os brancos faziam, quanto mais os negros! É que nem todos têm força para resistir: a natureza pode mais que a vontade humana (CAMINHA, 2009, p.52).

Há uma resposta mecânica, instintiva aos fatos e, nesse sentido, o livro perde um lado da questão, o que não esmaece sua força e valor literário. Reside nesse aspecto a explicação pela modificação de comportamento de Amaro, que age por instinto, tendo seu comportamento modificado, o que leva ao final trágico do relacionamento entre este e Aleixo um "belo marinheiro de olhos azuis, de quem se dizia coisas". Amaro nutre pelo rapaz um grande amor. Quando se conhecem, Aleixo tem cerca de 15 anos. Era filho de família de pescadores de Santa Catarina. O personagem é caracterizado com fortes traços de feminilidade, sendo loiro, de olhos azuis. Chega até a uma representação da mulher idealizada dos românticos. Aleixo é, ainda, a representação da passionalidade, por isso é denominado pelos demais marinheiros como "o boy". Nos primeiros capítulos, ele é retratado como ingênuo, mas no decorrer da narrativa sofre alterações 
comportamentais, passando a ser amante de Dona Carolina.

\section{Considerações finais}

A obra de Caminha é problematizadora, porque tratou de um tema extremamente intocável até então, o homossexualismo. A esse respeito, Dória (1997) pontua que autores malditos não são um privilégio deste século. Adolfo Caminha trata na obra de um tema extremamente rejeitado pelo cânone literário. "Adolfo Caminha cria uma tensão moderna entre as instituições carcomidas e a vida privada: seja a sua vida sexual - pela qual optou, abandonando a Marinha - , seja a de seu personagem Amaro, ambas evidenciando que a sociedade saída da escravidão estava longe de perder a feição totalitária (DÓRIA, 1997)".

Para dimensionar a trajetória de Amaro, sua trajetória é descrita como tentativa de autoafirmação, uma vez que se trata de um exescravo que engaja na marinha. O negro é retratado socialmente a lume de ideais deterministas, mas por outro lado, é retratado com requintes de superioridade pelo retrato forte e extremamente masculino. Contudo, tem alterado seu comportamento em decorrência de relacionar-se amorosamente com Aleixo. Nesse sentido, mais do que condenar e tratar como perversão, Caminha retrata a relação entre os dois marinheiros de forma ambígua, haja a vista a passionalidade levar à destruição dos personagens. Justamente a fusão entre o negro e a homossexualidade faz com que a obra ganhe o reconhecimento de romance maldito por ser a síntese do "politicamente incorreto" representado pelo romance, gênero que se revigora e abarca as mais diversas possibilidades de técnicas por ser o gênero que representa o herói fragmentado.

https://periodicos.unifap.br/index.php/letras

Macapá, v. 7, n. 4, 2ㅇsemestre, 2017 


\section{Referências}

ABDALLA, B. CAMPEDELLI, S.Y. Tempos de Literatura Brasileira. São Paulo. Ática, 2004.

AMARAL, E. MARTINS, G. Literatura para Unicamp 2002. São Paulo: Ateliê, 2001.

CAMINHA, A. Bom Crioulo. São Paulo: Martin Claret, 2009.

CAMPEDELLI, S.Y e SOUZA, J.R. Literatura, Produção de Texto e Gramática. São Paulo: Saraiva, 1999.

D'ONOFRIO, S. Teoria do texto 1: Prolegômenos e teoria narrativa. São Paulo: Ática, 1995.

DÓRIA, C.A. Crioulo, Marinho e gay. Folha de S. Paulo, 10 ago. 1997. MIGUEL-PEREIRA, L. Adolfo Caminha-Trechos escolhidos. Rio de Janeiro: Agir, 1960.

OLIVEIRA. S. Realismo na Literatura Brasileira. Curitiba: IESDE: 2008.

Recebido em 17/06/2017

Aceito em 14/09/2017

(ISSN 2238-8060) 